NASA/TM-2003-212109

\title{
Preliminary Results of a Microgravity Investigation to Measure Net Charge on Granular Materials
}

Robert D. Green and Jerry G. Myers

Glenn Research Center, Cleveland, Ohio

Bonnie L. Hansen

Parks College of Saint Louis University, Saint Louis, Missouri 
Since its founding, NASA has been dedicated to the advancement of aeronautics and space science. The NASA Scientific and Technical Information (STI) Program Office plays a key part in helping NASA maintain this important role.

The NASA STI Program Office is operated by Langley Research Center, the Lead Center for NASA's scientific and technical information. The NASA STI Program Office provides access to the NASA STI Database, the largest collection of aeronautical and space science STI in the world. The Program Office is also NASA's institutional mechanism for disseminating the results of its research and development activities. These results are published by NASA in the NASA STI Report Series, which includes the following report types:

- $\quad$ TECHNICAL PUBLICATION. Reports of completed research or a major significant phase of research that present the results of NASA programs and include extensive data or theoretical analysis. Includes compilations of significant scientific and technical data and information deemed to be of continuing reference value. NASA's counterpart of peerreviewed formal professional papers but has less stringent limitations on manuscript length and extent of graphic presentations.

- TECHNICAL MEMORANDUM. Scientific and technical findings that are preliminary or of specialized interest, e.g., quick release reports, working papers, and bibliographies that contain minimal annotation. Does not contain extensive analysis.

- CONTRACTOR REPORT. Scientific and technical findings by NASA-sponsored contractors and grantees.
- CONFERENCE PUBLICATION. Collected papers from scientific and technical conferences, symposia, seminars, or other meetings sponsored or cosponsored by NASA.

- SPECIAL PUBLICATION. Scientific, technical, or historical information from NASA programs, projects, and missions, often concerned with subjects having substantial public interest.

- TECHNICAL TRANSLATION. Englishlanguage translations of foreign scientific and technical material pertinent to NASA's mission.

Specialized services that complement the STI Program Office's diverse offerings include creating custom thesauri, building customized databases, organizing and publishing research results ... even providing videos.

For more information about the NASA STI Program Office, see the following:

- Access the NASA STI Program Home Page at http://www.sti.nasa.gov

- E-mail your question via the Internet to help@sti.nasa.gov

- Fax your question to the NASA Access Help Desk at 301-621-0134

- Telephone the NASA Access Help Desk at 301-621-0390

- Write to:

NASA Access Help Desk

NASA Center for AeroSpace Information 7121 Standard Drive

Hanover, MD 21076 
NASA/TM-2003-212109

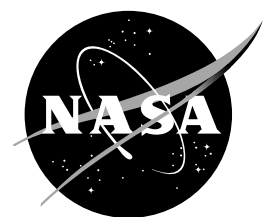

\section{Preliminary Results of a Microgravity Investigation to Measure Net Charge on Granular Materials}

Robert D. Green and Jerry G. Myers

Glenn Research Center, Cleveland, Ohio

Bonnie L. Hansen

Parks College of Saint Louis University, Saint Louis, Missouri

Prepared for the

41st Aerospace Sciences Meeting and Exhibit

sponsored by the American Institute of Aeronautics and Astronautics

Reno, Nevada, January 6-9, 2003

National Aeronautics and

Space Administration

Glenn Research Center 


\section{Acknowledgments}

The following people at NASA Glenn Research Center are to thank for their help in the design, construction, and analysis aspects of the prototype rig: Glenda Yee, Leonard Gumennik, Art Birchenough, Juan Agui, Masami Nakagawa, Dick Delombard, and Eric Bauman. Also thank you to the Office of Physical and Biological Research (OPBR) for funding this effort.

Trade names or manufacturers' names are used in this report for identification only. This usage does not constitute an official endorsement, either expressed or implied, by the National Aeronautics and Space Administration.

Available from

NASA Center for Aerospace Information 7121 Standard Drive

Hanover, MD 21076
National Technical Information Service 5285 Port Royal Road Springfield, VA 22100 


\title{
PRELIMINARY RESULTS OF A MICROGRAVITY INVESTIGATION TO MEASURE NET CHARGE ON GRANULAR MATERIALS
}

\author{
Robert D. Green and Jerry G. Myers \\ National Aeronautics and Space Administration \\ Glenn Research Center \\ Microgravity Science Division \\ Cleveland, Ohio 44135 \\ Email: Robert.D.Green@nasa.gov \\ Email: Jerry.G.Myers@nasa.gov \\ Bonnie L. Hansen \\ Parks College of Saint Louis University \\ Saint Louis, Missouri 63108 \\ Email: $\underline{\text { hansenbl@slu.edu }}$
}

\begin{abstract}
Accurate characterization of the electrostatic charge on granular materials has typically been limited to materials with diameters on the order of $10 \mu \mathrm{m}$ and below due to high settling velocities of larger particles. High settling velocities limit both the time and the acceptable uncertainty with which a measurement can be made. A prototype device has been developed at NASA Glenn Research Center (GRC) to measure coulombic charge on individual particles of granular materials that are 50 to 500 microns in diameter. This device, a novel extension of Millikan's classic oil drop experiment, utilizes the NASA GRC 2.2 second drop tower to extend the range of electrostatic charge measurements to accommodate moderate size granular materials. A dielectric material with a nominal grain diameter between 106 and 250 microns was tribocharged using a dry gas jet, suspended in a $5 \times 10 \times 10 \mathrm{~cm}$ enclosure during a 2.2 second period of microgravity and exposed to a known electric field. The response was recorded on video and post processed to allow tracking of individual particles. By determining the particle trajectory and velocity, estimates of the coulombic charge were made. Over 30 drops were performed using this technique and the analysis showed that first order approximations of coulombic charge could successfully be obtained, with the mean charge of 3.4E-14 coulombs measured for F-75 Ottawa quartz sand. Additionally, the measured charge showed a near-Gaussian distribution, with a standard deviation of 2.14E-14 Coulombs.
\end{abstract}

\section{INTRODUCTION}

That an investigation of electrostatic charge on granular materials is of research interest is in some sense, surprising. Even though frictional charging of materials has been well known for over
3000 years, we still do not understand its causes. ${ }^{1}$ Hence our motivation for a preliminary study to measure charge on granular type materials.

A number of industrial and aerospace applications require a better understanding of the electrostatic properties of granular and aerosol particles. Electrostatic paint systems, inkjet and laser jet printing systems and the $\mathrm{Xerox}^{\mathrm{TM}}$ process used in photocopiers require precise control of electrostatically charged solid or liquid particles. Design of efficient, i.e. low pressure drop, air filtration systems involve understanding the electrostatic properties of dust in a pneumatic driven flow system; an example is $3 \mathrm{M}^{\text {'s }}$ Filtrete ${ }^{\mathrm{TM}}$ product line of filters for residential heating and air conditioning applications which utilizes electrostatic-charged fibers to achieve filtration down to the 0.3 micron size level. ${ }^{2}$ The pharmaceutical industry routinely designs and operates equipment that transports and handles granular media in the form of fine powders and tablets. In the agricultural industry, application of pesticides involves flow of granular media in fine powder and liquid droplet forms and adherence to the target crop involves electrostatic forces combined with other adhesion forces.

Several potential NASA missions, in particular, planetary missions to either the Moon or Mars, require a fundamental understanding of granular flow and the potential electrostatic effects on these flows. A number of aerospace applications requiring granular flows support technological developments for the Space Science (SSE) and Human Exploration and Development of Space (HEDS) Enterprises. Reducing or mitigating dust contamination of space suits, equipment such as solar arrays, and crew habitat will be necessary for a manned mission to the Moon or Mars. A number of ISRU (In-Situ Resource Utilization) applications 
to support manned or sample return planetary missions involve handling and processing of granular materials. Chemical processing of planetary atmospheres, such as oxygen production from the carbon dioxide in the Martian atmosphere, will require efficient filtration of very fine atmospheric dust. For utilization of the planetary regolith, a whole host of processes will require direct handling of granular media.

A number of techniques have been used to measure electrostatic charge on particles. Flagan ${ }^{3}$ provides an extensive review of electrical measurements on aerosols, focusing on the Faraday cup electrometer and mobility analyzers used to measure charge on atmospheric gas ions and very small aerosol particles. Cross ${ }^{4}$ discusses the Faraday cup, Millikan method, deflection methods, and laser Doppler anemometry for measuring charge and mobility of individual aerosol or dust (solid) particles. Of these, the Millikan method provides the ability to measure charge on individual particles along with sampling statistically significant populations in a relatively short time. Millikan ${ }^{5}$ initially developed this technique with silicone oil drops to first measure the magnitude of the electron charge, a fundamental physical constant. Hopper and Laby ${ }^{6}$ modified the technique, using a horizontal (perpendicular to gravity) instead of vertical electric field to improve charge measurement accuracy. Kunkel ${ }^{7,8}$ and Kunkel and Hansen ${ }^{9}$ measured the charge levels on quartz dust and ammonium chloride aerosol particles up to 10 microns in diameter using an apparatus similar to Hopper and Laby's. McDonald et al. ${ }^{10}$ utilized Millikan cells to measure charge on fly ash particles ( 0.3 to $1.5 \mu \mathrm{m}$ diameter) after they were passed through a laboratory precipitator. Cross and Peterson ${ }^{11}$ performed similar work on brown coal fly ash particles (up to $8 \mu \mathrm{m}$ ) and reported consistency in measurements of their rotatable Millikan cell with measurements in a Faraday cup. More recently, Polat et al. ${ }^{12}$ measured charge on spray droplets $(\sim 50$ to $125 \mu \mathrm{m})$ of distilled water and aqueous surfactant solutions using a horizontal electrical field Millikan cell.

In all this work, the particle sizes were limited to $10 \mu \mathrm{m}$ for quartz sand and similar geological type materials (with densities $\sim 2.5 \mathrm{gm} / \mathrm{cm}^{3}$ ) or up to $100 \mu \mathrm{m}$ for lower density aerosol particles like water droplets. The factor limiting this particle size is the gravity force which shortens the residence time the particle spends in a horizontal electrical field (generated by vertical electrode plates). This limits the horizontal deflection the particle experiences, which is necessary to make an accurate charge measurement.

In this work, we illustrate a method to extend the maximum size of particles measured from 10 to 100 to 300 microns in diameter. It is also shown that charge measurements can be made simultaneously on a large number of particles during a single experiment, allowing the range of population charge levels to be obtained, while minimizing the effects of rapid charge decay. This data is necessary to assess granular medium aggregation phenomena in fractional gravity environments where charge forces on larger particles begin to approach gravity forces in magnitude.

\section{METHODS}

\section{Background Theory}

The method utilized in this technique is based on the balance between forces exerted on a particle, similar to the approach taken in Millikan's classic oil drop experiment. In this case, the forces under consideration are the electrostatic forces and the aerodynamic drag forces exerted on the particle.

In the absence of gravitational and other external forces, a particle with coulombic charge $q$, positioned in a uniform electric field of strength $E$, will be acted on by an electrostatic force that is parallel to the electric field and equivalent to

$$
F_{E}=q E
$$

When suspended in air, particle movement will result in an aerodynamic drag force in the opposite direction of the particle's trajectory. If the particle is spherical and its velocity is slow, i.e., in the creeping flow (Stokes flow) regime, the drag force obeys Stokes Law and is equivalent to

$$
F_{D}=6 \pi \mu \frac{D}{2} V
$$

where $\mu$ is the dynamic viscosity of air, $D$ is the diameter of the particle and $V$ is the steady state (terminal) velocity of the particle. It is noted at this time that the added mass and integral history components of the drag force and any inertial lift effects are neglected.

Under steady state conditions, these forces should balance, i.e. the particle should achieve a steady state velocity that is parallel to the electric field when the electrostatic force on the particle balances the viscous drag force on the particle. 
In other words, steady state is achieved when $F_{E}=F_{D}$ or

$$
q E=6 \pi \mu \frac{D}{2} V
$$

This balance allows the columbic charge on the particle to be calculated as

$$
q=\frac{6 \pi \mu \frac{D}{2} V}{E}
$$

provided the particle's diameter and steady state velocity parallel to a known electric field can be determined. It is noted that this analysis also applies to a particle with a non-zero settling velocity (perpendicular to the electric field), as long as the flow around the particle remains in the Stokes regime.

The application of this approach requires that sufficient time exist for the particle to reach terminal velocity. Using Newton's second law, it can be shown that the instantaneous particle velocity discussed above is given by the equation

$$
\begin{aligned}
v(t) & =\frac{F_{E}}{6 \pi \mu D / 2}\left[1-e^{-\beta t}\right]+v_{0} e^{-\beta t} \\
& =V\left[1-e^{-\beta t}\right]+v_{0} e^{-\beta t}
\end{aligned}
$$

where $v_{0}$ represents the initial particle velocity at time $t=0$ and $\beta$ is the inverse of the characteristic time constant $(\tau)$ defined as

$$
\beta=\frac{1}{\tau}=\frac{18 \mu}{\rho D^{2}}
$$

where $\rho$ is the particle's density. Setting $v(t)=$ $0.99 \mathrm{~V}, v_{0}=0$ and solving for $t$, a conservative estimate for the time required for the particle to reach $99 \%$ of the terminal velocity is given by the equation

$$
t_{99}=\frac{4.6052}{\beta}=4.6052 \cdot \tau
$$

Therefore, a particle that exhibits a characteristic time less than 0.48 seconds should reach $99 \%$ of its terminal velocity within 2.2 seconds, the duration of the microgravity period in the NASA GRC drop tower.

\section{Experimental Apparatus}

For this study, a Millikan cell chamber (internal dimensions $5 \times 10 \times 10 \mathrm{~cm}$ ) was constructed from polycarbonate and nylon (see Figures 1 and 2). Two parallel electrodes consisted of $10 \times 10 \mathrm{~cm}$ copper plates placed $5 \mathrm{~cm}$ apart. An E-field generator (or high voltage power supply) was built in-house from a series of DC-DC converters (Pico Electronics, Inc., Pelham, New York) to provide a voltage range of 50 to $2900 \mathrm{~V}$. Power was provided by a $28 \mathrm{~V}$ power supply on the drop rig. Above the cell, a tribocharging/hopper chamber was fabricated consisting of a cylindrical polycarbonate chamber with a nylon insert sloped like a chute to funnel the material sample into the Millikan (or E-field) chamber. Frictional charging (or tribocharging) was accomplished with a jet of dry air provided through a 0.25 in. stainless tube penetrating the center of the hopper chamber lid. This air jet was actuated with a solenoid valve and regulated from 5 to 20 psig with a pressure regulator. The dry air gas was stored on-board the drop rig at a pressure of $100 \mathrm{psig}$ in two $300 \mathrm{cc}$ gas cylinders.

\section{Sample Preparation}

The sample granular material chosen for this work was F-75 Ottawa quartz sand (US Silica Corporation, Ottawa, Illinois), which is a wellcharacterized material commonly used in granular media research. The bulk sand was sieved in an ATM Model L3P sonic sifter (ATM Corporation, Milwaukee, Wisconsin) to produce the appropriate size ranges to be investigated. This study utilized a 106 to $250 \mu \mathrm{m}$ size and a 250 to $300 \mu \mathrm{m}$ particulate size, for which the characteristic time constants $(\tau)$ are 0.25 and 0.58 seconds respectively. After sifting, the samples were washed in a dilute solution of de-ionized water and Micro- $90^{\mathbb{B}}$ detergent (International Products Corporation, Burlington, New Jersey), rinsed in deionized water, and dried in a conventional oven to remove any fines or metallic particles left over from grinding processes. Samples were stored in a desiccator and kept in tightly closed containers to minimize moisture pickup from the ambient air.

\section{Experimental Procedure}

The silica samples were loaded into the hopper/tribocharger chamber (see Figure 2) prior to the drop rig being installed in its drag shield. The room temperature and humidity was monitored with a handheld sensor. Relative humidity ranged from 43 to $62 \%$. One to 3 minutes prior to the drop, 
the sample was agitated with a dry air jet at 5 to 20 psig for 30 to 60 seconds to facilitate tribocharging (i.e. frictional charging). A few seconds prior to the drop, a solenoid actuated door was opened to allow a stream of sample particles to flow into the lower E-field test chamber (see Figure 2). The E-field power supply was activated 0.2 to 0.5 seconds after drop initiation (i.e. start of microgravity period) to allow particles to decelerate in the y direction in the absence of the gravity force. Particles were imaged using a 30 frames/sec Pulnix model TMC-7DSP video camera (PULNiX America, Sunnyvale, California) fitted with a Schneider 12.5 to $75 \mathrm{~mm}$ zoom lens. After acquisition, the analog image data was converted to digital AVI files using VirtualDub, ${ }^{*}$ a video capture software program. Particle displacements vs. time were extracted from the digital video images using Spotlight, ${ }^{\dagger}$ an in-house image tracking software program.

\section{RESULTS}

Approximately 30 drops were performed to test the prototype device and attempt to measure charge. Of these, 11 were deemed unsuitable for analysis due to mechanical problems with the apparatus or procedural errors. Of the remaining 19 successful drops, 12 were analyzed to determine appropriate particle tracking approaches, to estimate charge on individual particles and to test for sample charge distribution. The remaining 7 drops have not been analyzed to date. The experimental conditions pertaining to each of the analyzed drops are presented in Table 1 and include the particle size, granular sample volume, the delay from the time the drop was initiated to the time the E-field was activated, and the tribocharging period prior to the drop. Generally a random sample of between 15 and 20 particles was analyzed for each experiment.

Figure 3 illustrates a typical sequence of events observed prior to and during the microgravity drop procedure. Figure 3(a) shows that just prior to the drop, a column of particles is formed as the particle sample flows from the hopper under the influence of gravity. Once the drop has initiated, flow from the hopper stops, the column of particles slows noticeably and the column begins to elongate as the particles with higher momentum continue moving downward. By the time of E-field activation ( 0.3 seconds after drop initiation), the particle column has stretched substantially as illustrated by comparing in

\footnotetext{
* See http://www.virtualdub.org/

† See http://microgravity.grc.nasa.gov/spotlight/
}

Figure 3(b) and (c). After E-field activation, the particle column disperses rapidly in the lateral direction, as particles with various charges move in response to the applied electric field (Figure 3(d)). This continues throughout the drop (Figures 3(e) to 3(h)) with particles moving to both the left and right of the initial column position. Many particles can be seen to have impacted and adhered to one of the charged electrodes on the right side of Figure 3(h). This sequence of events was seen in all the successful drops where an E-field was applied.

Qualitatively, Figure 3 illustrates that the particles exhibit electrostatic charge and they respond as expected to the applied E-field. A more quantitative analysis was obtained by examination of individual particle trajectories. As a baseline, one drop was performed without tribocharging the sample and with no applied E-field (Drop \#5). A typical particle trajectory from this drop is shown in Figure 4, where the $\mathrm{x}$ (horizontal) and $\mathrm{y}$ (vertical) displacement of the particle is plotted versus time (time measured relative to the time during the drop the first position measurement was obtained). Both displacements illustrate continued movement in both directions during the drop. Although the displacement in the $\mathrm{x}$ direction is fairly small, ideally, no $\mathrm{x}$ displacement would be seen. However, because no E-field was applied, only particles that had been sheared away from the column due to viscous forces could be tracked.

Once an E-field is applied, as in drop \#7 (E-field of $100 \mathrm{~V} / \mathrm{cm}$, Figure 5(a)), many particles respond to the induced force. Displacements of these particles are in some cases similar to those seen for no applied E-field. However, many more particles can be accurately tracked because of the break up of the particle column. The terminal velocity of individual particles was obtained by performing a linear regression on the last 0.5 to 1 sec of the particle's measured $\mathrm{x}$ displacement. Regressions that produced correlation coefficients $\left(R^{2}\right)$ values in excess of 0.99 were assumed to represent a steady state velocity for the particle. The solid line in Figure 5(a) illustrates charge calculations determined in this manner for drop \#7. Figure 5(b) shows the charge distribution of all particles measured from drop \#7 (no tribocharging). When tribocharging is undertaken (as in drop \#8) the typical $x$ displacement of the particles increases slightly (Figure 6(a)), and, as expected, there is an observed increase in the charge level distribution across the particle population (Figure 6(b)). This indicates that the action of tribocharging the material sample before the drop does increase the charge level in the 
sample population. Additionally, these results indicate that even if the charge tends to dissipate after tribocharging, a residual charge remains on the particles for an extended period (seconds to minutes). It is noted that the total velocity (from both $\mathrm{x}$ and $\mathrm{y}$ components) was used to calculate the Reynolds number based on estimated particle diameter throughout the particles trajectory. Generally, it was found that $\mathrm{Re}<1$ for the experimental conditions used in this study.

Increasing the E-field strength effectively increases the typical particle $\mathrm{x}$ deflection and increases the spread of measured charge, as was expected (Figures 7 and 8). Although using both 200 and $400 \mathrm{~V} / \mathrm{cm}$ E-fields produced broader charge histograms, the most significant charge level remained in the region of 3E-14 coulombs. This indicates a good reproducibility for the system and of the methods employed to produce and measure charge. Examination of the measured charge from all drops (Figure 9) illustrates a mean charge of 3.4E-14 coulombs (standard deviation of $2.14 \mathrm{E}-14$ coulombs) and an overall distribution similar in shape to those found from the higher Efield experiments.

\section{DISCUSSION}

Previous reports of charge measurements on particulate media have utilized a number of different techniques to initially charge and measure the charge distribution. Kunkel, ${ }^{7}$ by a controlled release of dust particles ( 1 to $10 \mu \mathrm{m}$ ) into a known electric field, obtained Gaussian distributions of charge level and measured a mean net charge of 250 electron units $(4.0 \mathrm{E}-17 \mathrm{C})$ on $5 \mu \mathrm{m}$ diameter quartz sand. McDonald et al. ${ }^{10}$ measured levels an order of magnitude higher than this for $2 \mu \mathrm{m}$ diameter fly ash particles, but these particles were charged using a corona device. In some recent work, Sickenfoose et al. ${ }^{13}$ have observed a Gaussian distribution of charge levels for JSC-1 dust simulant material with mean charge of 6E-15 C for 90-106 $\mu \mathrm{m}$ size particles. Sternovsky et al. ${ }^{14}$ have measured charge levels of 5-6E-14 C for 100 to $120 \mu \mathrm{m}$ diameters of this same material; charge measurements for both of these studies were made with a Faraday cup. Unfortunately, direct comparison of the current effort and those of previously published works is difficult because of different charging mechanisms, different materials, and typically smaller particle sizes than those examined in this study. Regardless of these limitations, the results shown for charge distribution are very similar (near-Gaussian) to those reported by other researchers. Charge magnitudes measured in this study are several orders of magnitude higher than reported in the literature for smaller particles. However, they match closely with charges measured on particles of similar size, but of different materials. Further characterization of other materials with tighter size distributions should provide more insight into the comparability of charge measurements with this method and those mentioned above.

Each of the individual particle traces sampled in this experiment exhibited similar characteristics. Generally, the 2 sec microgravity period allows larger particles to slow considerably in the vertical direction, therefore, remaining exposed to the E-field for a longer period of time. As expected, this allows the particles to experience larger horizontal displacements than is feasible in horizontal E-field Millikan cells under normal gravity conditions. Also, the particle distribution in the y direction is reasonably dispersed, due to the stretching of the initial particle column, which minimizes particle-to-particle interactions that may interfere with the critical $\mathrm{x}$-displacement tracking necessary for an accurate charge measurement. A preliminary error analysis of the charge calculation procedure indicates that variation in particle diameter is the largest contributor, with uncertainty in E-field magnitude and particle terminal velocity making much smaller contributions $(<10 \%$ of total error). The first can be improved with better material preparation and selection, while the second may be merely an overly conservative estimate of the precision of the home-built E-field power supply. Overall, the total uncertainty of a charge measurement based on this approach is expected to be less than $\pm 1.3 \mathrm{E}-14 \mathrm{C}$.

A significant strength of this system appears to be the ability to randomly sample a number of particles in the same experiment simultaneously, which illustrates that charge level in the population is a significant parameter. With variations of as much as two orders of charge magnitude in the same experiment, the frictional charging approach used in this application may not be well characterized, although near-Gaussian distributions were evident for each individual experiment. Additionally, rapid charge decay may play a role in this large variation, but this has not been verified. In duplicating an individual experiment with a higher E-field, we found that we could obtain a better (i.e. broader) representation of the charge distribution, due to lower charged particles experiencing a measurable $\mathrm{x}$-displacement they would not undergo at lower E-field settings; the data collected enhanced the Gaussian distribution on the lower end. This demonstrates that a large range of charge distributions can be adequately 
measured by varying the E-field setting and also illustrates the reproducibility.

Although it is believed that electrostatic charge was successfully measured on individual grains of material, there are several limitations to the current prototype device and the employed methodology. The current approach assumes that the particle does not exceed the Stokes criteria (i.e. $\operatorname{Re}<<1$ ) and that the fluid effects of "added mass" and integral particle history can be neglected. It is expected that neglecting these effects will result in, at most, a $\sim 10 \%$ error on the charge measurement. However, if the total particle velocity is such that the Stokes regime is exceeded, estimates of the coulombic charge can still be made, but more complicated drag force calculations are required. Further, the requirement that a particle must reach a terminal velocity before a charge level can be estimated, severely limits the number and the type of particles that can be analyzed. It is believed that by including the particle acceleration and drag history in the derivation of particle displacement, a suitable estimate of the charge can be determined. The design of the prototype apparatus also limits application to certain size particles, primarily due to imaging limitations. Based on the current characterization, it is believed that refinements to the field of view and camera resolution will address these concerns. Finally, the sign of the particle charge was not considered in this preliminary analysis. Generally, particles attracted to the positively charged electrode were analyzed (i.e. negatively charged particles). However, qualitatively speaking, video images indicate that roughly a 50/50 split in charge sign is exhibited. This will be more quantitatively investigated in future efforts.

\section{CONCLUSIONS}

A newly developed prototype device that uses a novel extension of Millikan's classic oil drop experiment in combination with brief periods of microgravity, illustrates that electrostatic charge measurements are possible on moderately sized (>100 microns) dielectric particles. Using this device, the population charge distribution for F-75 Ottawa quartz was shown to be near Gaussian, with a mean charge level of 3.4E-14 $\mathrm{C}$ and standard deviation of $2.14 \mathrm{E}-14 \mathrm{C}$, which compared well with measurements reported in the literature for particles of similar size, but differing materials. When tribocharging, or frictional charging, of the particle population was used prior to making charge measurements, the charge level was found to increase and the population charge distribution grew. While the prototype device and methods currently have a narrow range of application (with regard to particle size, particle type, etc.), many of the procedures utilized are well-established in microgravity fluid physics research, such as methodologies for particle tracking and data reduction. Future efforts will seek to extend the range of particle diameters that can be measured, to diameters larger than those dictated by the terminal velocity requirement. Because a particle that continues accelerating throughout the drop period (2.2 seconds) should have a unique particle response to the E-field, we are confident that we can measure charge on particles up to $500 \mu \mathrm{m}$ in diameter with densities near the density of quartz or glass $(2.5 \mathrm{gm} / \mathrm{cc})$, and $800+\mu \mathrm{m}$ for materials with lower densities like polycarbonate. More diverse particle types and better characterization of the particle diameters are also needed. Use of commercially available glass beads, better sieving techniques, image based particle sizing techniques, and use of the particle deceleration in the y-direction (to estimate size), would allow better individual particle classification. A wider range of materials such as hematite, a significant component in Mars regolith, or one or more of the so-called Mars or Lunar simulant soils prepared by NASA JSC, are also under consideration for testing. Finally we would like to take a closer look at improving the precision of our measurements by reducing our major sources of error, particle diameter (using the aforementioned techniques) and the uncertainty in the E-field strength. In general, our apparatus was crude, but note that Millikan was able to measure the electron charge to $4.7992 \pm 0.0037 \mathrm{E}-10$ esu over 85 years ago using an "eye and hand" method. It is hoped that with modern digital video imaging capabilities and tighter control over the particle characteristics, our efforts can achieve moderately similar success.

\section{REFERENCES}

1. J.A. Cross, Electrostatics: Principles, Problems, and Applications, Adam Hilger, Bristol, England, 1987, p. 17.

2. see $3 \mathrm{M}$ web site, http://www.3M.com/us/home_leisure/filtrete/ index.html

3. R.C. Flagan, "History of Electrical Aerosol Measurements," Aerosol Science and Technology, 28, 301 (1998). 
4. J.A. Cross, Electrostatics: Principles, Problems, and Applications, Adam Hilger, Bristol, England, 1987, p. 108-115.

5. R.A. Millikan, "On the Elementary Electrical Charge and the Avogadro Constant," Phys. Rev., 2, 109 (1913).

6. Hopper, V.D. and Laby, R.H., "The Electronic Charge," Proc. Roy. Soc. A, 178, 243 (1941).

7. Kunkel, W.B., "The Static Electrification of Dust Particles on Dispersion in a Cloud," Journal of Applied Physics, 21, 820 (1950).

8. Kunkel, W.B., "Charge Distribution in Coarse Aerosols as a Function of Time," Journal of Applied Physics, 21, 833 (1950).

9. Kunkel, W.B. and Hansen, J.W., "A Dust Electricity Analyzer," The Review of Scientific Instruments, 21, 308 (1950).

10. J.R. McDonald, M.H. Anderson, R.B. Mosley, and Leslie Sparks, "Charge Measurements on Individual Particles Exiting Laboratory Precipitators with Positive and Negative Corona at Various Temperatures," Journal of Applied Physics, 51, 3632 (1980).
11. J. Cross and L. Peterson, "Evaluation of the Millikan Method to Measure the Relationship Between the Electrostatic Charge and Aerodynamic Radius of Brown Coal Fly Ash," Proceedings of the 8th International Clean Air Conference (Melbourne, Australia), 1984 (Melbourne: Holmes).

12. M. Polat, H. Polat, and S. Chander, "Electrostatic Charge on Spray Droplets of Aqueous Surfactant Solutions," Journal of Aerosol Science, 31, 551 (2000).

13. A. Sickafoose, J. Colwell, M. Horanyi, and S. Robertson, "Experimental Investigations on Photoelectric and Triboelectric Charging of Dust," Journal of Geophysical Research, 106, 8343 (2001).

14. Z. Sternovsky, S. Robertson, A. Sickafoose, J. Colwell, and M. Horanyi, "Contact Charging of Lunar and Martian Dust Simulants," Journal of Geophysical Research, 107, (E11), 5105, doi: 10.1029/2002JE001897, 2002.

Table 1: Experimental conditions for all analyzed drops.

\begin{tabular}{|c|c|c|c|c|c|c|c|c|}
\hline Drop \# & $\begin{array}{c}\text { Particle } \\
\text { Diameter } \\
(\text { microns })\end{array}$ & $\begin{array}{c}\text { Sample } \\
\text { Size } \\
(\mathrm{ml})\end{array}$ & $\begin{array}{c}\text { Temp } \\
{ }^{\circ} \mathrm{C}\end{array}$ & $\begin{array}{c}\text { Relative } \\
\text { Humidity } \\
(\%)\end{array}$ & $\begin{array}{c}\text { E-Field } \\
(\mathrm{V} / \mathrm{cm})\end{array}$ & $\begin{array}{c}\text { E-Field } \\
\text { Delay } \\
(\mathrm{sec})\end{array}$ & $\begin{array}{c}\text { Tribocharge } \\
\text { Time (sec) }\end{array}$ & $\begin{array}{c}\# \text { of } \\
\text { Particles } \\
\text { Analyzed }\end{array}$ \\
\hline 1 & $106-250$ & 100 & 26 & 57 & 200 & 0.2 & 0 & 14 \\
\hline 2 & $106-250$ & 50 & 26 & 62 & 200 & 0.2 & 0 & 5 \\
\hline 3 & $106-250$ & 50 & 24 & 54 & 0 & 0 & 0 & 6 \\
\hline 5 & $106-250$ & 50 & 27 & 50 & 0 & 0 & 0 & 7 \\
\hline 6 & $106-250$ & 50 & 26 & 43 & 200 & 0.3 & 42 & 13 \\
\hline 7 & $106-250$ & 50 & 22 & 54 & 100 & 0.3 & 0 & 16 \\
\hline 8 & $106-250$ & 50 & 24 & 48 & 100 & 0.5 & 45 & 15 \\
\hline 12 & $106-250$ & 50 & 27 & 45 & 200 & 0.3 & 45 & 15 \\
\hline 13 & $106-250$ & 50 & 24 & 62 & 400 & 0.3 & 0 & 20 \\
\hline 14 & $106-250$ & 50 & 26 & 57 & 400 & 0.3 & 60 & 20 \\
\hline 15 & $106-250$ & 50 & 26 & 57 & 200 & 0.3 & 60 & 15 \\
\hline 30 & $250-300$ & 30 & 23 & 46 & 200 & 0.3 & 60 & 15 \\
\hline
\end{tabular}




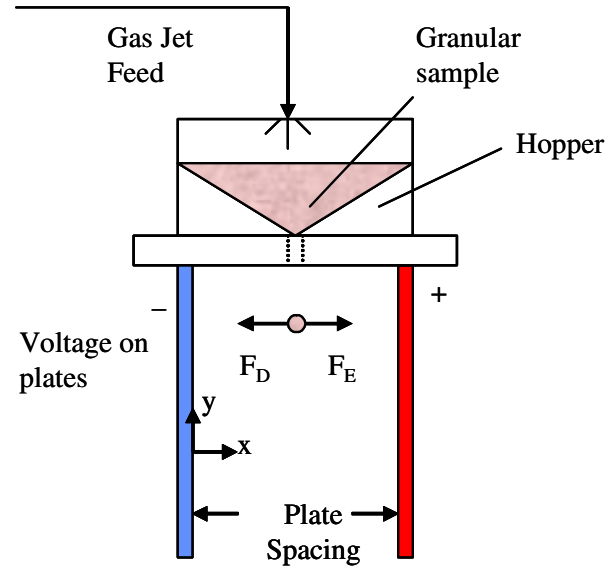

Figure 1. Illustration of columbic charge measurement. The particle samples are released from the hopper after tribocharging with the dry gas jet. As the particle moves between the charged plates, it is acted on by two primary forces, the force due to the electric field and the drag force. Note that the coordinate axis shown on the left is a indication of the $\mathrm{x}$ and $\mathrm{y}$ directions, not of the origin used in the analysis.

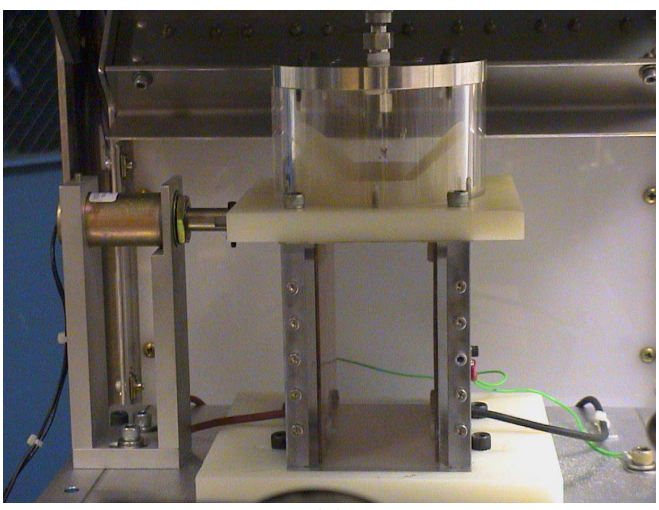

(a)

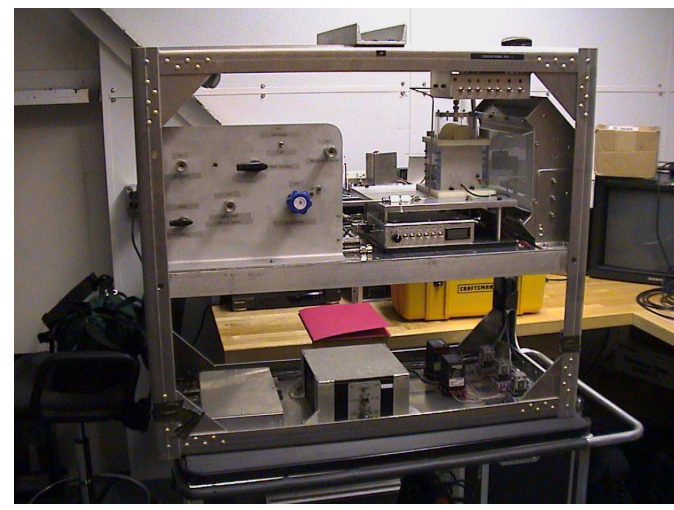

(b)

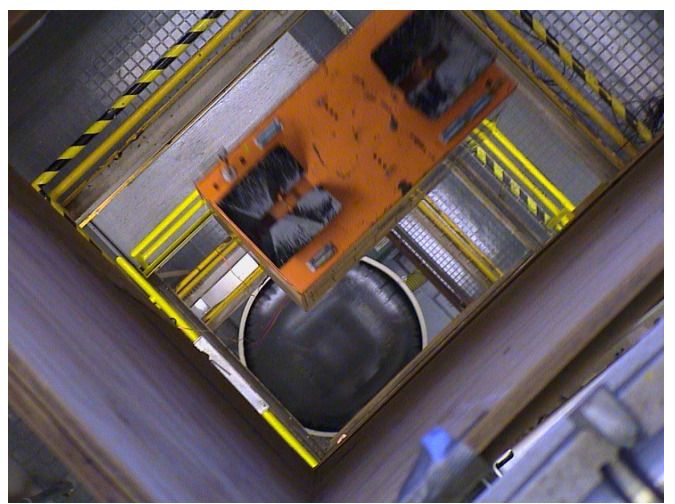

(c)

Figure 2. Pictures of the columbic charge measurement device (a) as viewed from the camera location (b) assembled on the DIME education drop rig and (c) after being placed in drag shroud and dropped in the NASA-GRC 2.2 second Drop Tower. In (a), to the left is the solenoid that opens the hopper door.

Behind the device, the back light used for illumination is seen. The sample hopper and dry gas jet are located above the chamber. Note the chamber is $5 \mathrm{~cm}$ wide, $10 \mathrm{~cm}$ high and $10 \mathrm{~cm}$ deep. 


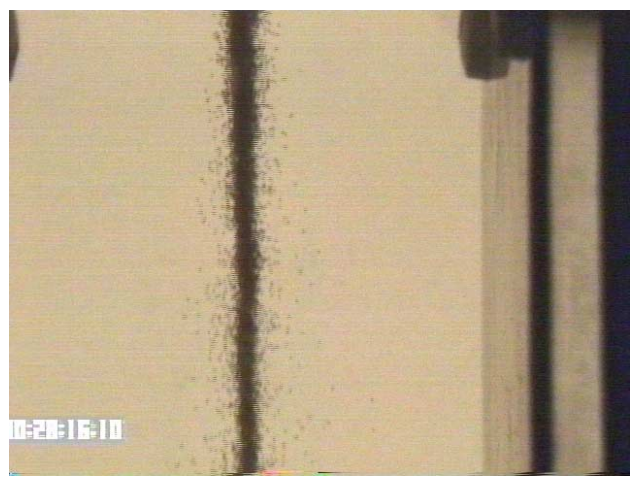

(a) Before Drop

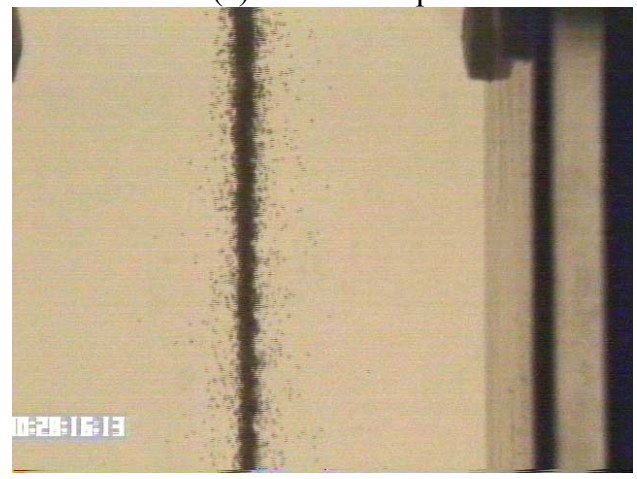

(b) Initiation of Drop

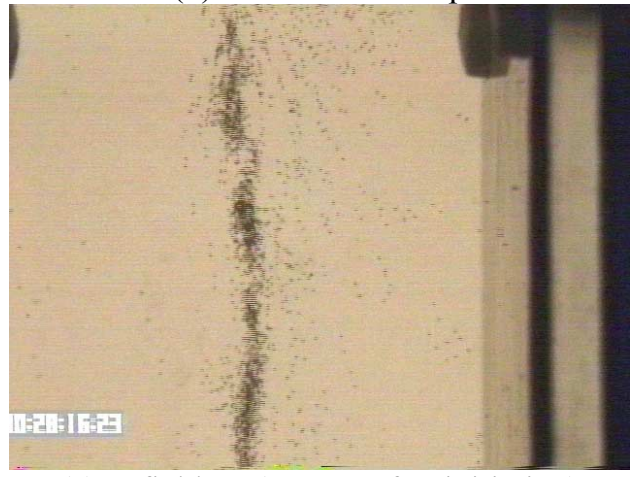

(c) E-field on (0.3 sec after initiation)

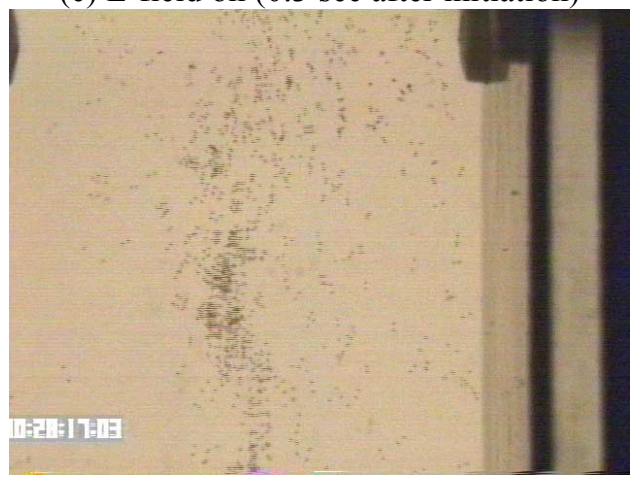

(d) $0.33 \mathrm{sec}$ after E-field activation

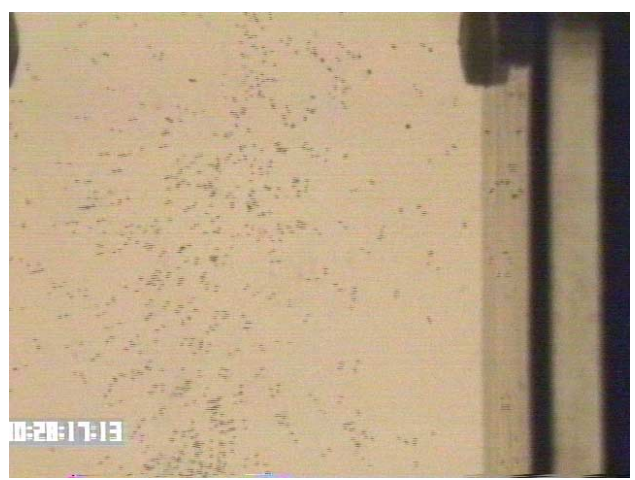

(e) $0.66 \mathrm{sec}$ after E-field activation

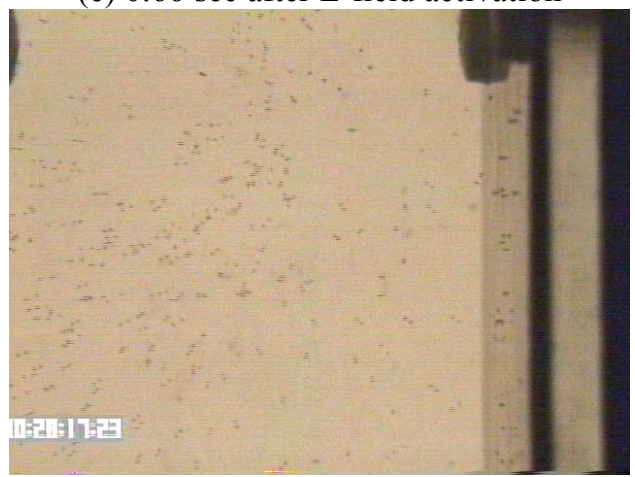

(f) $0.99 \mathrm{sec}$ after E-field activation

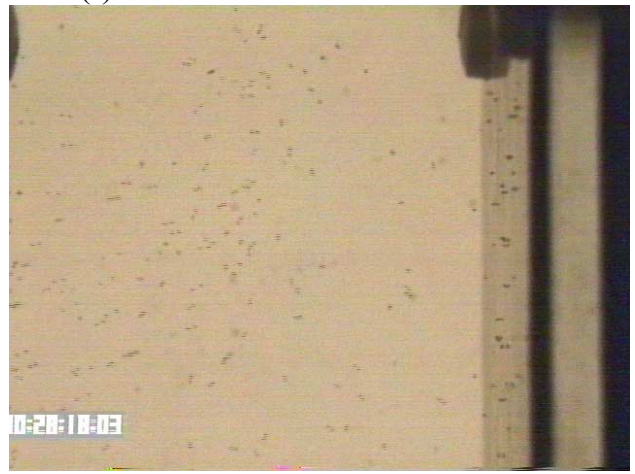

(g) $1.32 \mathrm{sec}$ after E-field activation

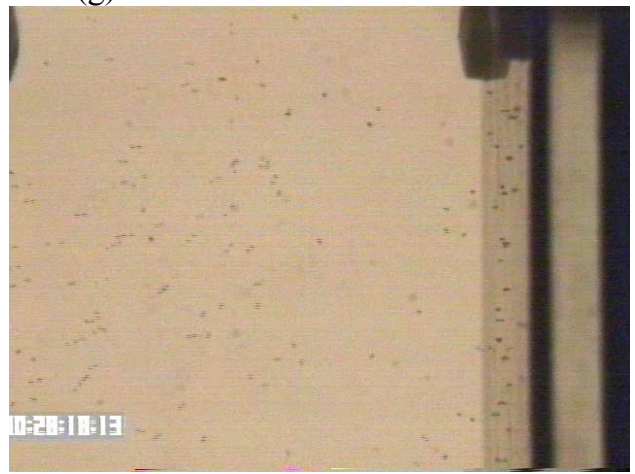

(h) $1.65 \mathrm{sec}$ after E-field activation

Figure 3. Images acquired during typical drop experiment. Before this drop $\sim 30 \mathrm{~mL}$ of sand (250 to $300 \mu \mathrm{m}$ ) was tribocharged for $\sim 1$ minute using a dry gas jet. The electric field strength was $200 \mathrm{~V} / \mathrm{cm}$ and the ambient humidity was measured as $46 \%$. 


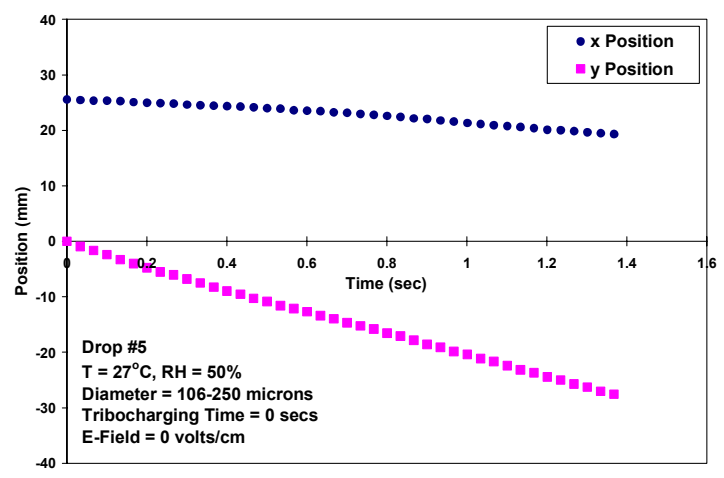

Figure 4. Typical "baseline" particle trajectory exhibited during the microgravity period. This example is considered baseline since a zero electric field was applied and samples had not undergone tribocharging.

Note Time $=0$ in this case represents the time from which the particle tracking started.

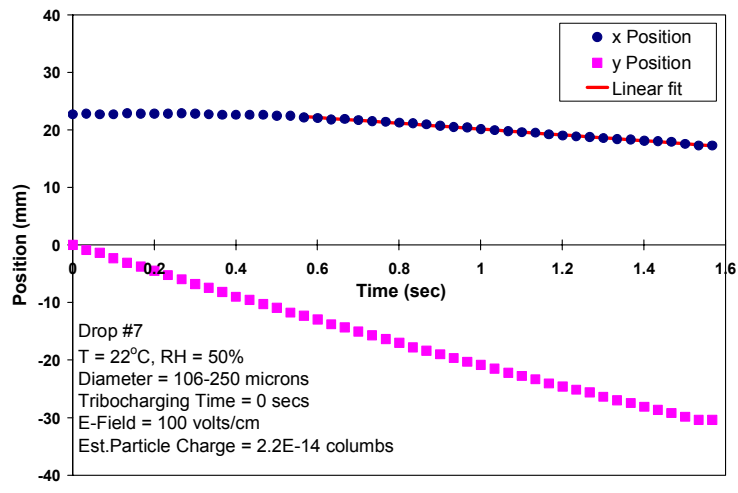

(a)

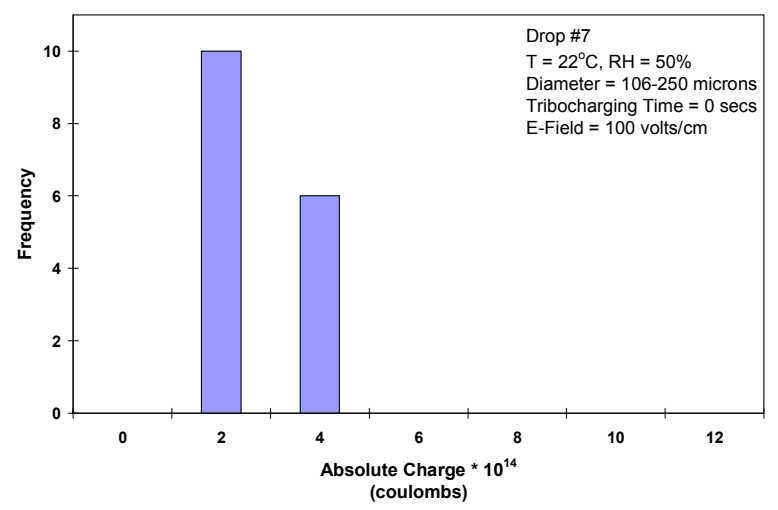

(b)

Figure 5. Results of "No Tribocharging" charge measurements made during a microgravity period: (a) shows a typical particle track and (b) shows the distribution of charge. An electric field of $100 \mathrm{~V} / \mathrm{cm}$ was applied to the particle cloud and an estimate of the particle charge was made by evaluating the particle terminal velocity in the $\mathrm{x}$-direction by linear regression of the last 1 second of $\mathrm{x}$-position data. Note Time $=0$ in this case represents the time from which the particle tracking started.

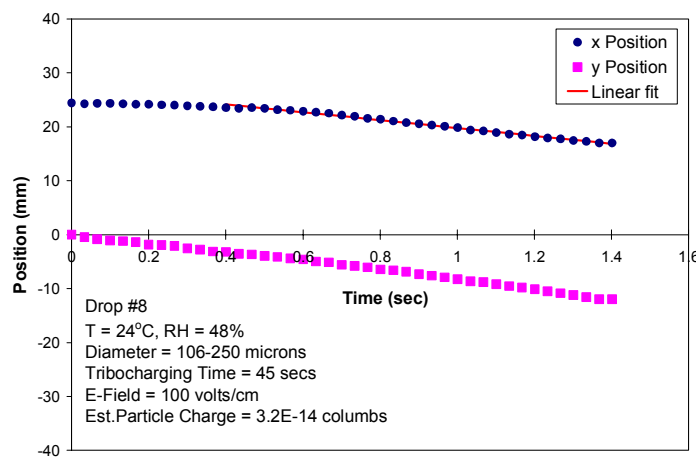

(a)

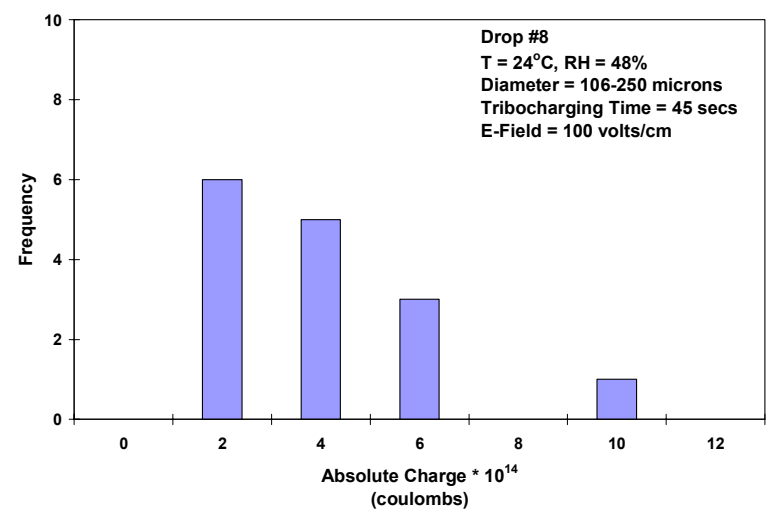

(b)

Figure 6. Results of "Tribocharging" using a low electric field: (a) shows a typical particle track and (b) shows the charge distribution. An electric field of $100 \mathrm{~V} / \mathrm{cm}$ was applied to the particle cloud and an estimate of the particle charge was made by evaluating the particle terminal velocity in the $\mathrm{x}$-direction by linear regression of the last 1 second of $\mathrm{x}$-position data. Note Time $=0$ in this case represents the time from which the particle tracking started. 


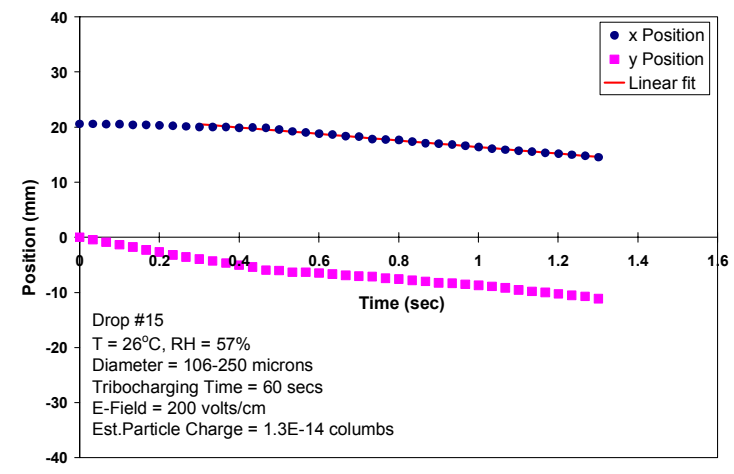

(a)

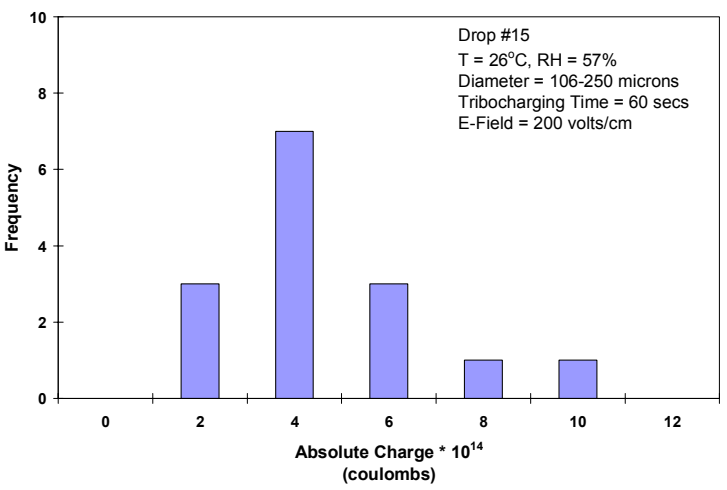

(b)

Figure 7. Results of "Tribocharging" using a moderate electric field: (a) shows a typical particle track and (b) shows the charge distribution. An electric field of $200 \mathrm{~V} / \mathrm{cm}$ was applied to the particle cloud and an estimate of the particle charge was made by evaluating the particle terminal velocity in the $\mathrm{x}$-direction by linear regression of the last 1 second of $\mathrm{x}$-position data. Note Time $=0$ in this case represents the time from which the particle tracking started.

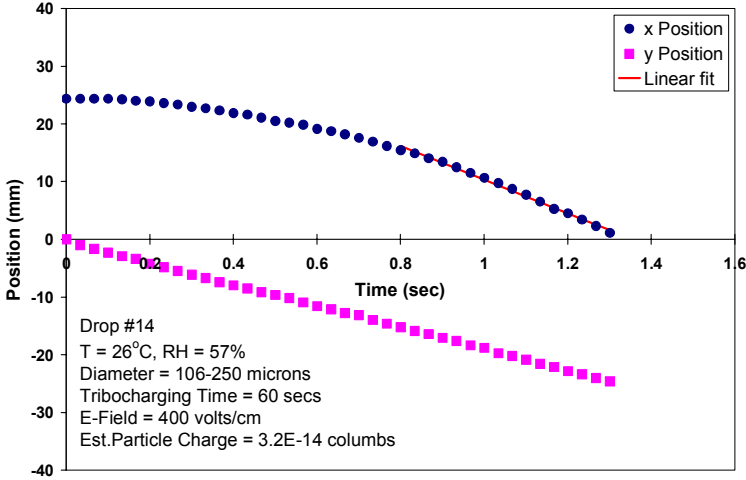

(a)

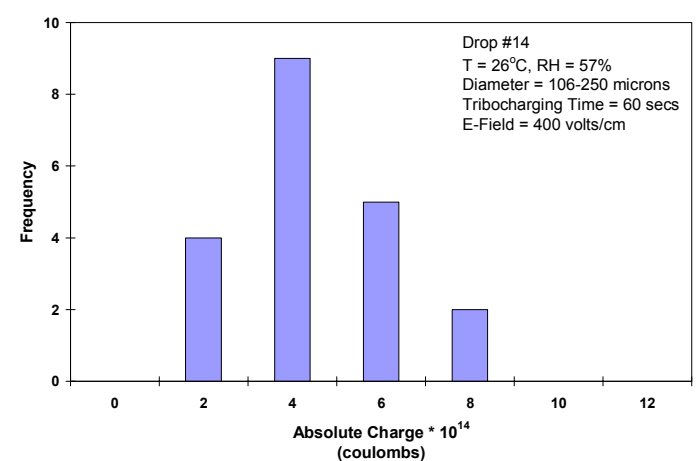

(b)

Figure 8. Results of "Tribocharging" using a high electric field: (a) shows a typical particle track and (b) shows the charge distribution. An electric field of $400 \mathrm{~V} / \mathrm{cm}$ was applied to the particle cloud and an estimate of the particle charge was made by evaluating the particle terminal velocity in the $\mathrm{x}$-direction by linear regression of the last 1 second of $\mathrm{x}$-position data. Note Time $=0$ in this case represents the time from which the particle tracking started.

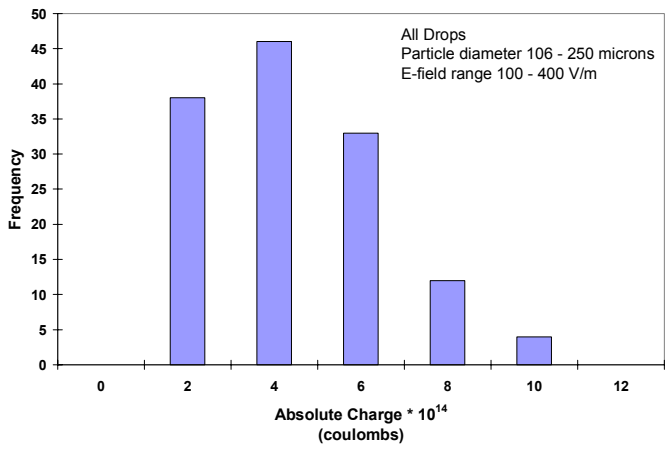

Figure 9. Histogram of charge measurements from all drops performed, including tribocharged and non-tribocharged samples. 
Public reporting burden for this collection of information is estimated to average 1 hour per response, including the time for reviewing instructions, searching existing data sources, gathering and maintaining the data needed, and completing and reviewing the collection of information. Send comments regarding this burden estimate or any other aspect of this collection of information, including suggestions for reducing this burden, to Washington Headquarters Services, Directorate for Information Operations and Reports, 1215 Jefferson Davis Highway, Suite 1204, Arlington, VA 22202-4302, and to the Office of Management and Budget, Paperwork Reduction Project (0704-0188), Washington, DC 20503.

\begin{tabular}{|l|l|l|}
\hline 1. AGENCY USE ONLY (Leave blank) & $\begin{array}{c}\text { 2. REPORT DATE } \\
\text { January } 2003\end{array}$ & $\begin{array}{r}\text { 3. REPORT TYPE AND DATES COVERED } \\
\text { Technical Memorandum }\end{array}$ \\
\hline
\end{tabular}

\section{TITLE AND SUBTITLE}

\section{FUNDING NUMBERS}

Preliminary Results of a Microgravity Investigation to Measure Net Charge on Granular Materials

6. AUTHOR(S)

Robert D. Green, Jerry G. Myers, and Bonnie L. Hansen

WBS-22-101-53-01

7. PERFORMING ORGANIZATION NAME(S) AND ADDRESS(ES)

National Aeronautics and Space Administration

John H. Glenn Research Center at Lewis Field

Cleveland, Ohio 44135-3191

8. PERFORMING ORGANIZATION

REPORT NUMBER

E-13760

\section{SPONSORING/MONITORING AGENCY NAME(S) AND ADDRESS(ES)}

National Aeronautics and Space Administration

Washington, DC 20546-0001

10. SPONSORING/MONITORING AGENCY REPORT NUMBER

NASA TM-2003-212109

AIAA-2003-1304

\section{SUPPLEMENTARY NOTES}

Prepared for the 41st Aerospace Sciences Meeting and Exhibit sponsored by the American Institute of Aeronautics and Astronautics, Reno, Nevada, January 6-9, 2003. Robert D. Green and Jerry G. Myers, NASA Glenn Research Center, and Bonnie L. Hansen, Parks College of Saint Louis University, Saint Louis, Missouri 63108. Responsible person, Robert D. Green, organization code 6712, 216-433-5402.

12a. DISTRIBUTION/AVAILABILITY STATEMENT

12b. DISTRIBUTION CODE

Unclassified - Unlimited

Subject Categories: 34, 45, and 90

Distribution: Nonstandard

Available electronically at http://gltrs.grc.nasa.gov

This publication is available from the NASA Center for AeroSpace Information, 301-621-0390.

\section{ABSTRACT (Maximum 200 words)}

Accurate characterization of the electrostatic charge on granular materials has typically been limited to materials with diameters on the order of $10 \mu \mathrm{m}$ and below due to high settling velocities of larger particles. High settling velocities limit both the time and the acceptable uncertainty with which a measurement can be made. A prototype device has been developed at NASA Glenn Research Center (GRC) to measure coulombic charge on individual particles of granular materials that are 50 to 500 microns in diameter. This device, a novel extension of Millikan's classic oil drop experiment, utilizes the NASA GRC 2.2 second drop tower to extend the range of electrostatic charge measurements to accommodate moderate size granular materials. A dielectric material with a nominal grain diameter between 106 and 250 microns was tribocharged using a dry gas jet, suspended in a $5 \times 10 \times 10 \mathrm{~cm}$ enclosure during a 2.2 second period of microgravity and exposed to a known electric field. The response was recorded on video and post processed to allow tracking of individual particles. By determining the particle trajectory and velocity, estimates of the coulombic charge were made. Over 30 drops were performed using this technique and the analysis showed that first order approximations of coulombic charge could successfully be obtained, with the mean charge of 3.4E-14 coulombs measured for F-75 Ottawa quartz sand. Additionally, the measured charge showed a near-Gaussian distribution, with a standard deviation of $2.14 \mathrm{e}-14$ coulombs.

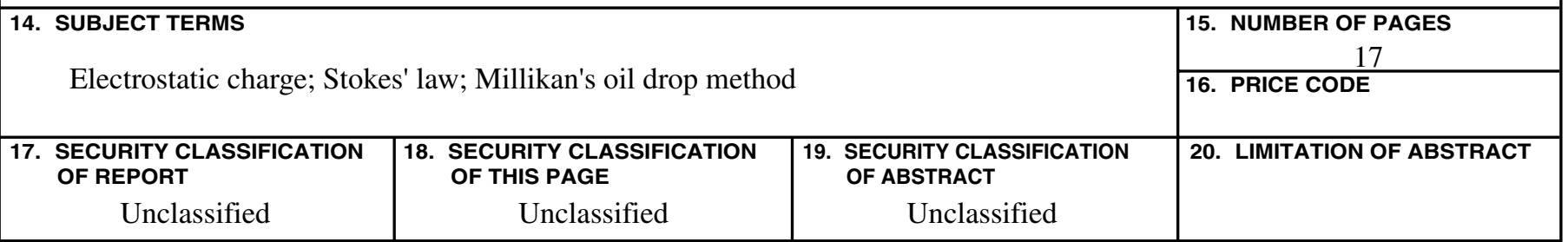

NSN 7540-01-280-5500

Standard Form 298 (Rev. 2-89)

Prescribed by ANSI Std. Z39-18 298-102 

